\title{
A COVID-19 exposure at a dental clinic where healthcare workers routinely use particulate filtering respirators
}

\author{
Do Sup Kim \\ Konkuk University Medical Center \\ Jae-Hoon Ko \\ Samsung Medical Center \\ Kyong Ran Peck \\ Samsung Medical Center \\ Jin Yang Baek \\ Asia Pacific Foundation for Infectious Diseases \\ Hee-Won Moon \\ Konkuk University Medical Center \\ Hyun Kyun Ki \\ Konkuk University Medical Center \\ Ji Hyun Yoon \\ Konkuk University Medical Center \\ Hyo Jin Kim \\ Konkuk University Medical Center \\ Jeong Hwa Choi \\ Konkuk University Medical Center \\ Ga Eun Park ( $\square$ kaeun84@gmail.com ) \\ Konkuk University Medical Center
}

\section{Research Article}

Keywords: COVID-19, SARS-CoV-2, Exposure, Dental, Particulate filtering respirator

Posted Date: December 16th, 2020

DOI: https://doi.org/10.21203/rs.3.rs-107927/v1

License: (c) (i) This work is licensed under a Creative Commons Attribution 4.0 International License. Read Full License 


\section{Abstract}

Back ground. Asymptomatic/mildly symptomatic coronavirus disease 2019 (COVID-19) patients produce a considerable amount of virus and transmit severe acute respiratory syndrome virus 2 (SARS-CoV-2) through close contact. Preventing in-hospital transmission of SARS-CoV-2 is challenging, since symptom-based screening protocols may miss asymptomatic/mildly symptomatic patients. In particular, dental health workers (HCWs) are at high risk of exposure, as face-to-face contact and exposure to oral secretions is unavoidable. We report exposure of HCWs during dental procedures on a mild symptomatic COVID-19 patient.

Methods. A 32-year old male visited a dental clinic at a tertiary care hospital. He experienced mild cough, which started three days before the dental visit, but did not report his symptom during the entrance screening. He underwent several dental procedures and imaging for orthognathic surgery without wearing a mask. Seven HCWs were closely exposed to the patient during dental procedures that could have generated droplets and aerosols. One HCW had close contact with the patient during radiologic exams, and seven HCWs had casual contact. All HCWs wore particulate filtering respirators with $94 \%$ filter capacity and gloves, but none wore eye protection or gowns. The next day, the patient experienced dysgeusia and was diagnosed with COVID-19 with high viral load.

Results. All HCWs who had close contact with the patient were quarantined for 14 days, and polymerase chain reaction and antibody tests for SARS-CoV-2 were negative.

Conclusion. This exposure event suggests the protective effect of particulate filtering respirators in dental clinics. The appropriate personal protective equipment for routine patient care during COVID-19 pandemic should be established. The appropriate personal protective equipment for routine patient care during COVID-19 pandemic should be established.

\section{Introduction}

Since the first report of severe acute respiratory syndrome coronavirus 2 (SARS-CoV-2) infection in Wuhan, China, in December 2019, there has been a global outbreak of coronavirus disease 2019 (COVID-19) [1]. The typical transmission pathways of SARS-CoV-2 include direct inhalation of droplets and contact between contaminated hands and the nasal, oral, and ocular mucosa [2-5]. When aerosols are generated in a closed area, aerosol transmission may be another route of infection [6]. Recent studies showed that SARS-CoV-2 can be transmitted by asymptomatic patients who generate few droplets [7-9]. Since symptom-based screening protocols may be ineffective at identifying asymptomatic or mildly symptomatic patients, these patients act as hidden transmission focuses despite vigorous infection containment measures [7].

Healthcare workers (HCWs) at dental clinics are at high risk of unexpected exposure. Regular dental treatments lead to close face-to-face contact with patients not wearing masks. Frequent utilization of vibrating devices may produce aerosols, and body fluids such as blood and saliva can spatter into the eyes. Despite the precautions taken, it is impossible to entirely prevent the production of droplets and aerosols during dental procedures [10]. Evidence regarding the effectiveness of personal protective equipment (PPE) for dental HCWs during routine patients care during the COVID-19 pandemic is still insufficient. Herein, we report an exposure situation of HCWs during dental procedures on a mildly symptomatic COVID-19 patient with high viral load.

\section{Methods}




\section{Contact tracing, quarantine, and tests for SARS-CoV-2 infection}

After being made aware of SARS-CoV-2 exposure at the dental clinic, we immediately performed thorough contact tracing of the COVID-19 patient. All exposed HCWs, patients, and visitors were identified. We evaluated the degree of contact, such as exposure situation and time, adequacy of PPE, and the presence of any COVID-19-related symptoms. The exposed persons were divided into quarantine (close and unprotected exposure) and active monitoring (distant or protected exposure) groups [11]. Quarantined HCWs were subjected to reverse-transcriptase polymerase chain reaction (RT-PCR) for SARS-CoV-2 at the start and the end of a two-week quarantine. Serologic tests for SARS-CoV-2 were performed one to two months after the end of quarantine. A fluorescent immunoassay (FIA) kit for anti-SARS-CoV-2 IgM and IgG antibodies and an enzyme-linked immunosorbent assay (ELISA) kit for anti-SARS-CoV-2 total antibody were used. HCWs in the active monitoring group took RT-PCR tests on the day of exposure confirmation and were monitored for the development of COVID-19-related symptoms for two weeks. Informed consent was obtained from the HCWs for donated blood samples. This study was approved by the Institutional Review Board (IRB) of Samsung Medical Center (IRB No. SMC 2020-04-066). We also received consents to obtain blood from all participants. The data was anonymized before the study was conducted.

\section{RT-PCR assay}

RT-PCR assay (Seegene Inc., Seoul, South Korea) was performed according to the manufacturer's instructions. The primer and probe sequences were described in a previous study [12]. Each sample was defined as positive if the cycle threshold (Ct) was less than or equal to 35 cycles.

\section{FIA kit for anti-SARS-CoV-2 IgM and IgG antibodies}

To detect anti-SARS-CoV-2 IgM and IgG antibodies among exposed HCWs, we used a FIA kit (AFIAS COVID-19 Ab assay, Boditech Med Inc., Chuncheon, Korea). The FIA IgM and IgG kit used automated fluorescent lateral flow immunoassay method, using the AFIAS-6 analyzer system [13]. This assay uses a sandwich immunoassay with a detector SARS-CoV-2 protein (recombinant nucleocapsid proteins with europium chelate). Specimens with a relative cut-off index $(\mathrm{COI})$ value $\geq 1.1$ were considered positive. All procedures were performed according to the manufacturer's instructions.

\section{ELISA total antibody kit}

The ELISA total antibody kit (PCL COVID-19 Total Ab EIA test, PCL Inc, Seoul, Korea) detects total antibody against nucleocapsid protein and receptor binding domain (RBD) of the spike protein of SARS-CoV-2 using the sandwich immunoassay method. An optical density (OD) ratio $<1.0$ was interpreted as negative, $\geq 0.9$ to $<1.0$ as borderline, and $\geq 1.0$ as positive. All tests were performed according to the manufacturer's instructions.

\section{Results}

\section{Description of the exposure situation at our hospital}

Patient A was a 32-year-old man. On May 11, 2020, he visited a dental clinic at a tertiary care medical center for a consult prior to orthognathic surgery. Although he experienced mild cough three days before the hospital visit, he did not report this symptom during the entrance screening at the hospital. He had a consultation with a dental surgeon and necessary dental procedures as preparation for orthognathic surgery in the dental clinic from 13:30 to 14:45. He underwent chest X-ray, blood sampling, and facial computed tomography (CT) scanning from 14:45 to 15:20. After that, he returned to the dental department for orthodontic treatment. The first step was pre-consultation examination 
in the oral and maxillofacial surgery department, which included dental impressions, intraoral photographs, extraoral photographs, dental X-rays, wax bite taking, and face-bow transfer. The second step was face-to-face consultation with a professor and one assistant. The third step was orthodontic treatment in the orthodontic department including a dental bonding procedure and orthodontic wire change. During these dental procedures, Patient A did not wear a face mask. After all the procedures were over, he was given a verbal summary of future treatment procedures. He left the clinic at 16:40. The next morning, the patient developed dysgeusia and his dry cough worsened. He underwent RT-PCR for SARS-CoV-2. On May 13, 2020, he was confirmed to have SARS-CoV-2 infection. The low Ct value on RT-PCR (22.38 for RdRp and 22.52 for E genes) suggested high viral load.

\section{Demographic and epidemiologic characteristics of HCWs under quarantine}

A total of 48 persons were identified as exposed, including $15 \mathrm{HCWs.} \mathrm{Eight} \mathrm{HCWs} \mathrm{were} \mathrm{quarantined} \mathrm{because} \mathrm{they}$ had contact with Patient A when he was not wearing a mask. The demographics and epidemiological characteristics of the exposed HCWs are summarized in Table 1. The median age of HCWs under quarantine was 42.5 years old (IQR 30.5-55.75), and four (50.0\%) were male. HCWs consisted of two dentists (25.0\%), one nurse (12.5\%), four oral hygienists (50.0\%), and one radiologic engineer (12.5\%). Five of these HCWs worked in the oral and maxillofacial surgery department, two HCWs in the orthodontic department, and one HCW in the radiologic department. All procedures are listed in Table 2, which shows, how long each task typically takes (time), whether HCWs talked faceto-face with Patient A (talking), and if a droplet was produced during the task (droplet), and whether direct face-toungloved hand contact (skin contact) or exposure to oral cavity (oral exposure) occurred. 
Table 1

Demographic and epidemiologic characteristics of HCWs under quarantine and active monitoring

\section{Exposed HCWs ( $\mathrm{n}$ HCWs in the quarantine \\ $=15)$ \\ group $(n=8)$}

\section{$\mathrm{HCWs}$ in the active \\ monitoring group}

$(n=7)$

\section{Demographics}

Age, years

$36(30-52)$

$43(31-56)$

$36(25-41)$

Male sex

$6(40.0)$

$4(50.0)$

$2(28.6)$

Underlying diseases

$2(13.3)$

$2(25.0)$

$0(0.0)$

Occupations

Doctor

$4(26.7)$

$2(25.0)$

$2(28.6)$

Nurse

1 (6.7)

1 (12.5)

$0(0.0)$

Oral hygienist

$4(26.7)$

$4(50.0)$

$0(0.0)$

Radiologic technician

$1(4.7)$

$1(12.5)$

$0(0.0)$

Laboratory technician

$5(33.3)$

$0(0.0)$

$5(33.3)$

\section{Exposure situation}

Dental clinic

Close contact for

examination

$7(6.7)$

$7(12.5)$

$0(0.0)$

Distant contact

$2(13.3)$

$0(0.0)$

$2(28.6)$

Outside the dental clinic

Close contact (blood $\quad 1(6.7)$

sample)

Close contact (CT scan)

$1(6.7)$

1 (12.5)

$0(0.0)$

Distant contact

4 (26.7)

$0(0.0)$

4 (57.1)

Patient A's mask

7 (46.7)

$0(0.0)$

7 (100)

wearing

\section{PPE of HCWs}

$\begin{array}{llll}\text { Mask/respirator } & 15(100) & 8(100) & 7(100) \\ \text { KF94 respirator } & 9(60.0) & 7(87.5) & 2(28.6) \\ \text { Surgical mask } & 6(40.0) & 1(12.5) & 5(71.4) \\ \text { Gloves } & 14(93.3) & 7(87.5) & 7(100)\end{array}$

Data are expressed as the number (\%) of patients or median (interquartile range). ${ }^{*}$ Within 14 days after exposure Abbreviations: HCWs, healthcare workers; CT, computed tomography; PPE, personal protective equipment; COVID-19, coronavirus disease 2019 


\begin{tabular}{|llll|}
\hline & $\begin{array}{l}\text { Exposed HCWs }(\mathbf{n} \\
=15)\end{array}$ & $\begin{array}{l}\text { HCWs in the quarantine } \\
\text { group }(\mathbf{n}=\mathbf{8})\end{array}$ & $\begin{array}{l}\text { HCWs in the active } \\
\text { monitoring group } \\
(\mathbf{n}=7)\end{array}$ \\
\hline Gown & $0(0.0)$ & $0(0.0)$ & $0(0.0)$ \\
\hline Eye protection & $0(0.0)$ & $0(0.0)$ & $0(0.0)$ \\
\hline $\begin{array}{l}\text { CoVID-19-related } \\
\text { symptoms }\end{array}$ & $1(6.7)$ & $1(12.5)$ & $0(0.0)$ \\
\hline $\begin{array}{l}\text { Data are expressed as the number (\%) of patients or median (interquartile range). } \\
\text { Abbreviations: HCWs, healthcare workers; CT, computed tomography; PPE, personal protective equipment; } \\
\text { COVVID-19, coronavirus disease 2019 }\end{array}$ \\
\hline
\end{tabular}


Table 2

Detailed description of dental procedures.

\begin{tabular}{|c|c|c|c|c|c|c|c|c|}
\hline & & & Time & Talking & Droplet & $\begin{array}{l}\text { Skin } \\
\text { contact }\end{array}$ & $\begin{array}{l}\text { Oral } \\
\text { exposure }\end{array}$ & $\begin{array}{l}\text { HCWs } \\
\text { (number) }\end{array}$ \\
\hline \multirow[t]{8}{*}{$\begin{array}{l}\text { Oral and } \\
\text { maxillofacial } \\
\text { department }\end{array}$} & \multirow[t]{6}{*}{$\begin{array}{l}\text { Pre- } \\
\text { consultation } \\
\text { examination }\end{array}$} & $\begin{array}{l}\text { Dental } \\
\text { impression }\end{array}$ & $<5$ min & 0 & 0 & 0 & 0 & $\begin{array}{l}\text { Oral } \\
\text { hygienist } \\
(1)\end{array}$ \\
\hline & & $\begin{array}{l}\text { Intraoral } \\
\text { photo }\end{array}$ & $<5$ min & 0 & 0 & 0 & 0 & $\begin{array}{l}\text { Oral } \\
\text { hygienist } \\
\text { (1) }\end{array}$ \\
\hline & & $\begin{array}{l}\text { Extraoral } \\
\text { photo }\end{array}$ & $<5 \min$ & 0 & $x$ & $x$ & $x$ & $\begin{array}{l}\text { Oral } \\
\text { hygienist } \\
(1)\end{array}$ \\
\hline & & $\begin{array}{l}\text { Dental X- } \\
\text { ray }\end{array}$ & $<5$ min & 0 & $x$ & 0 & $x$ & $\begin{array}{l}\text { Oral } \\
\text { hygienist } \\
\text { (1) }\end{array}$ \\
\hline & & Wax bite & $<5 \min$ & 0 & 0 & 0 & 0 & Nurse (1) \\
\hline & & Face bow & $<5 \min$ & 0 & 0 & 0 & 0 & $\begin{array}{l}\text { Dentist } \\
(1)\end{array}$ \\
\hline & \multicolumn{2}{|l|}{ Consultation } & $<0$ min & 0 & 0 & 0 & $x$ & $\begin{array}{l}\text { Oral } \\
\text { hygienist } \\
\text { (2) } \\
\text { Dentist } \\
\text { (1) }\end{array}$ \\
\hline & $\begin{array}{l}\text { Dental } \\
\text { procedure } \\
\text { summary }\end{array}$ & & $<$ & 0 & 0 & $x$ & $x$ & $\begin{array}{l}\text { Oral } \\
\text { hygienists } \\
\text { (3) }\end{array}$ \\
\hline \multirow[t]{4}{*}{$\begin{array}{l}\text { Orthodontic } \\
\text { department }\end{array}$} & \multirow[t]{4}{*}{$\begin{array}{l}\text { Orthodontic } \\
\text { treatment }\end{array}$} & $\begin{array}{l}\text { Dental } \\
\text { bonding }\end{array}$ & 30 min & 0 & 0 & 0 & 0 & $\begin{array}{l}\text { Oral } \\
\text { hygienist } \\
\text { (4) }\end{array}$ \\
\hline & & & & & & & & $\begin{array}{l}\text { Dentist } \\
\text { (2) }\end{array}$ \\
\hline & & $\begin{array}{l}\text { Wire } \\
\text { change }\end{array}$ & $<15$ min & 0 & 0 & 0 & 0 & $\begin{array}{l}\text { Oral } \\
\text { hygienist } \\
\text { (4) }\end{array}$ \\
\hline & & & & & & & & $\begin{array}{l}\text { Dentist } \\
\text { (2) }\end{array}$ \\
\hline
\end{tabular}

All HCWs under quarantine wore particulate filtering respirator with $94 \%$ filter capacity (KF94 respirator, approved by the Ministry of Food and Drug Safety (MFDS) of Korea, according to the criteria equivalent with the European Standard for FFP2 respirator), but did not wear eye protection or gowns. Patient A removed his face mask for various dental procedures. Since Patient A was not suspected to have COVID-19, each procedure was performed under normal safety precautions. Patient A was not wearing a mask during CT scanning, so the radiologic technician was also quarantined. One HCW complained of myalgia shortly after exposure, but improved within two days. 


\section{Laboratory test results}

All HCWs under quarantine and active monitoring underwent RT-PCR for SARS-CoV-2 four to five days from the date of exposure, and quarantined HCWs were tested again before the end of quarantine. The results of RT-PCR were all negative. Tests for anti-SARS-CoV-2 antibodies were performed on quarantined HCWs on the 52nd day from exposure. All serologic test results including FIA IgM and IgG and ELISA total antibody were negative.

\section{Discussion}

There are currently no data available to assess the risk of SARS-CoV-2 transmission and the prevalence of subclinical seroconversion of SARS-CoV-2 in a dental setting [14]. This is the first descriptive study on real-world exposure to SARS-CoV-2 during dental procedures. In this study, we also investigated seroconversion of SARS-CoV-2 infection in dental HCWs exposed to a mildy symptomatic SARS-CoV-2 patient while using particulate filtering respirators.

Routine application of particulate filtering respirators, such as N95 (US standard), FFP2 (European standard), KN95 (Chinese respirator equivalent to N95), or KF94 (Korean respirator equivalent to FFP2), to protect HCWs from respiratory viruses is controversial. A recent randomized controlled trial resulted in no significant difference between the effectiveness of $\mathrm{N} 95$ respirators and surgical masks in preventing influenza infection among participants routinely exposed to respiratory illnesses in a hospital setting [15]. However, faced with the COVID-19 pandemic, use of particulate filtering respirators in high-risk settings should be considered, as there has been some evidence of airborne transmission [16]. Dental practice requires the use of non-disposable dental and surgical instruments, such as handpieces, ultrasonic scalers, and air-water syringes. These instruments can scatter visible droplets that contain water, saliva, blood, microorganisms, and other debris. Surgical masks protect the mucous membranes of the mouth and nose from droplet splash, but they are unlikely to completely protect against the inhalation of virus-containing aerosols $[10,14,17,18]$. The Center for Disease Control and Prevention (CDC) released Guidance for Dental Settings on June 17, 2020, three months after the pandemic began. According to these guidelines, dental HCWs should wear a surgical mask, eye protection (goggles, protective eyewear with solid side shields, or a full-face shield), a gown, and gloves during patient care encounters, including those where splashes are not anticipated, in areas with moderate to substantial community transmission. During aerosol-producing procedures, dental HCWs should use N95-equivalent particulate filtering respirators or powered air purifying respirators, where available [14].

At the time of the exposure event reported herein, community transmission of SARS-CoV-2 was not a serious concern in the Republic of Korea. Although a cluster associated with clubs in Itaewon occurred two weeks before, most cases were traced and the number of new daily reported cases was < 50 [19]. As a result, guidance for PPE in dental clinics was not as stringent as the CDC has suggested. Although HCWs performed dental procedures or facial CT scanning while wearing only KF94 respirators and gloves, secondary infections did not occur. No HCWs showed seroconversion to SARS-CoV-2. Despite the lack of additional PPE and high viral load of Patient A, KF94 respirators, gloves, and hand hygiene seem to have prevented viral spread. KF94 respirator is a particulate filtering respirator with $94 \%$ filter capacity, approved by the MFDS of Korea [20-23]. The MFDS applied equivalent test criteria with the European Standard for FFP2 respirator (EN 149:2001) to the KF94 respirator (filtration efficiency, using sodium chloride $\geq 94 \%$ and paraffin oil $\geq 94 \%$; breathing resistance $\leq 70 \mathrm{~Pa}(30 \mathrm{~L} / \mathrm{min})$; and total inward leakage rate $\leq 11 \%)$ [21]. The Korean CDC has recommended that HCWs treating COVID-19 patients wear KF94 respirators to protect themselves against the SARS-CoV-2. However, as most KF94 respirators were designed and manufactured for casual use for protection against fine dust and air pollution before the COVID-19 outbreak, most products use ear 
loops rather than the headband used in N95 respirators [24]. KF94 respirators with ear loops are more comfortable for daily usage, but they fit looser than respirators with headbands. Currently, most HCWs caring for laboratoryconfirmed COVID-19 patients in Korea prefer to use N95 respirators, while KF94 respirators are widely used in routine clinical care and daily life. Although the relative safety of ear loops versus headbands remains controversial, KF94 respirators have advantages in daily use for the protection of HCWs in situations of community transmission of SARS-CoV-2.

Another reason why SARS-CoV-2 spread did not occur at our dental clinic is probably the difference in the degree of droplet and aerosol production depending on dental departments. Unlike the periodontal department and the conservative dentistry and prosthesis department, the use of high-speed handpieces is relatively low in the oral and maxilla-facial surgery and orthodontic department, especially for treatments related to orthognathic surgery. Patient A did not undergo typical dental procedures using a high-speed handpiece. All procedures were in preparation for orthognathic surgery. As shown in Table 2, the dental care he received encompassed talking, clinical photos, facing HCWs with mouth open, and dental bonding procedures with a low-speed handpiece only. Thus, there may have been less droplet and aerosol production than during periodontal procedures.

In the case of non-emergent issues, if a patient suspected to have COVID-19 visits a dental clinic, it is recommended that the dentist defers treatment for at least 14 days. Orthognathic surgery for treating jaw deformities is not a lifethreatening condition that must be treated urgently. One study recommended deferral of orthognathic surgery until the COVID-19 pandemic situation has settled [25]. However, these conditions can severely impact the quality of life of the person with the jaw deformity and surgical interventions cannot be delayed until the end of the pandemic. In dental practice that requires invasive procedures, it is advisable to wear the PPE recommended by the CDC regardless of the patient's condition. However, as the pandemic continues long-term, PPE supplies are limited. It is difficult and costly to use the recommended PPE for all dental patients. In order to preserve resources, different levels of PPE for dental HCWs have been applied according to the planned procedure, the risk of COVID-19 infection of the patient, and the outbreak situation of the community [25].

Our study had several limitations. As this was a dental procedure in the department of oral and maxillofacial surgery, production of droplets and aerosols would have been minimal. Only eight HCWs were quarantined. As there was no security camera in the dental clinic, the level of exposure was based on individual recollections.

\section{Conclusions}

Among HCWs exposed during dental procedures on a mildly symptomatic COVID-19 patient, there were no SARSCoV-2 infections. Routine usage of particulate filtering respirators in dental clinic could play a major role in preventing transmission. The effectiveness of PPE for daily patient care during the COVID-19 pandemic should be established depending on the outbreak situation of the community.

\section{Abbreviations}

COVID-19 : Coronavirus disease 2019 ; SARS-CoV-2 : Severe acute respiratory syndrome virus 2 ; HCWs : Healthcare workers ; PPE : Personal protective equipment ; RT-PCR : Reverse-transcriptase polymerase chain reaction ; FIA : fluorescent immunoassay ; ELISA : Enzyme-linked immunosorbent assay ; IRB : Institutional Review Board ; COI : Cutoff index ; RBD : Receptor binding domain ; OD : Optical density ; CT : Computed tomography ; MFDS : Ministry of Food and Drug Safety ; CDC : Center for Disease Control and Prevention 


\section{Declarations}

Ethics approval and consent to participate

Informed consent was obtained from the HCWs for donated blood samples. This study was approved by the Institutional Review Board (IRB) of Samsung Medical Center. The study was performed in accordance with the guidelines followed as per the Declaration of Helsinki.

Consent for publication

Consent for publication and sharing our data was obtained in association with consent to participate

Availability of data and materials

The datasets analyzed during the current study are available from the corresponding author on reasonable request.

Competing interests

All authors declare that they have no competing interest.

Funding

This work was supported as a Research Program funded by the Korea Centers for Disease Control and Prevention (\#2020-ER5328-00).

Acknowledgements

We would like to express our sincerest condolences to the patients and families affected by the COVID-19 outbreak. We greatly appreciate the HCWs who volunteered for blood sampling for this study. Finally, we would like to thank Boditech Med Inc. and PCL Inc. for their generous donation of antibody testing kits.

Authors' contributions

Conceptualization: D.S.K., J.-H.K., K.R.P., G.E.P.; investigation: D.S.K., H.-W.M., H.K.K., J.H.Y., H.J.K., J.H.C.; laboratory work and methodology: J.-H.K., J.Y.B., H.-W.M.; supervision: G.E.P.; writing-review and editing: D.S.K., J.-H.K., K.R.P., G.E.P. All authors have read and agreed to the publication of this manuscript.

\section{References}

1. Li Q, Guan X, Wu P, Wang X, Zhou L, Tong Y, Ren R, Leung KSM, Lau EHY, Wong JY et al: Early Transmission Dynamics in Wuhan, China, of Novel Coronavirus-Infected Pneumonia. The New England journal of medicine 2020, 382(13):1199-1207.

2. Lu CW, Liu XF, Jia ZF: 2019-nCoV transmission through the ocular surface must not be ignored. Lancet 2020, 395(10224):e39.

3. Li Y, Ren B, Peng X, Hu T, Li J, Gong T, Tang B, Xu X, Zhou X: Saliva is a non-negligible factor in the spread of COVID-19. Mol Oral Microbiol 2020.

4. To KK, Tsang OT, Chik-Yan Yip C, Chan KH, Wu TC, Chan JMC, Leung WS, Chik TS, Choi CY, Kandamby DH et al: Consistent detection of 2019 novel coronavirus in saliva. Clinical infectious diseases: an official publication of 
the Infectious Diseases Society of America 2020.

5. Huang C, Wang Y, Li X, Ren L, Zhao J, Hu Y, Zhang L, Fan G, Xu J, Gu X et al: Clinical features of patients infected with 2019 novel coronavirus in Wuhan, China. Lancet 2020, 395(10223):497-506.

6. Wang L, Wang Y, Ye D, Liu Q: Review of the 2019 novel coronavirus (SARS-CoV-2) based on current evidence. Int $J$ Antimicrob Agents 2020, 55(6):105948.

7. Gandhi M, Yokoe DS, Havlir DV: Asymptomatic Transmission, the Achilles' Heel of Current Strategies to Control Covid-19. New England Journal of Medicine 2020, 382(22):2158-2160.

8. Sakurai A, Sasaki T, Kato S, Hayashi M, Tsuzuki SI, Ishihara T, Iwata M, Morise Z, Doi Y: Natural History of Asymptomatic SARS-CoV-2 Infection. The New England journal of medicine 2020.

9. Rothe C, Schunk M, Sothmann P, Bretzel G, Froeschl G, Wallrauch C, Zimmer T, Thiel V, Janke C, Guggemos W et al: Transmission of 2019-nCoV Infection from an Asymptomatic Contact in Germany. The New England journal of medicine 2020, 382(10):970-971.

10. Fallahi HR, Keyhan SO, Zandian D, Kim SG, Cheshmi B: Being a front-line dentist during the Covid-19 pandemic: a literature review. Maxillofac Plast Reconstr Surg 2020, 42(1):12.

11. Park GE, Ko JH, Peck KR, Lee JY, Lee JY, Cho SY, Ha YE, Kang Cl, Kang JM, Kim YJ et al: Control of an Outbreak of Middle East Respiratory Syndrome in a Tertiary Hospital in Korea. Ann Intern Med 2016, 165(2):87-93.

12. Corman VM, Landt O, Kaiser M, Molenkamp R, Meijer A, Chu DK, Bleicker T, Brünink S, Schneider J, Schmidt ML et al: Detection of 2019 novel coronavirus (2019-nCoV) by real-time RT-PCR. Euro Surveill 2020, 25(3).

13. Ryu JH, Kwon M, Moon JD, Hwang MW, Lee JM, Park KH, Yun SJ, Bae HJ, Choi A, Lee H et al: Development of a Rapid Automated Fluorescent Lateral Flow Immunoassay to Detect Hepatitis B Surface Antigen (HBsAg), Antibody to HBsAg, and Antibody to Hepatitis C. Ann Lab Med 2018, 38(6):578-584.

14. Guidance for Dental Settings. Interim Infection Prevention and Control Guidance for Dental Settings During the COVID-19 Response. https://www.cdc.gov/coronavirus/2019-ncov/hcp/dental-settings.html Accessed on August 30, 2020.

15. Radonovich LJ, Jr., Simberkoff MS, Bessesen MT, Brown AC, Cummings DAT, Gaydos CA, Los JG, Krosche AE, Gibert CL, Gorse GJ et al: N95 Respirators vs Medical Masks for Preventing Influenza Among Health Care Personnel: A Randomized Clinical Trial. Jama 2019, 322(9):824-833.

16. Klompas M, Baker MA, Rhee C: Airborne Transmission of SARS-CoV-2: Theoretical Considerations and Available Evidence. Jama 2020, 324(5):441-442.

17. Sabino-Silva R, Jardim ACG, Siqueira WL: Coronavirus COVID-19 impacts to dentistry and potential salivary diagnosis. Clin Oral Investig 2020, 24(4):1619-1621.

18. Villani FA, Aiuto R, Paglia L, Re D: COVID-19 and Dentistry: Prevention in Dental Practice, a Literature Review. Int $J$ Environ Res Public Health 2020, 17(12).

19. Kang CR, Lee JY, Park Y, Huh IS, Ham HJ, Han JK, Kim JI, Na BJ: Coronavirus Disease Exposure and Spread from Nightclubs, South Korea. Emerg Infect Dis 2020, 26(10).

20. Kim MC, Bae S, Kim JY, Park SY, Lim JS, Sung M, Kim SH: Effectiveness of surgical, KF94, and N95 respirator masks in blocking SARS-CoV-2: a controlled comparison in 7 patients. Infect Dis (Lond) 2020:1-5.

21. MFDS: Diagnostics Devices, MFDS-regulated Mask Information, https://www.mfds.go.kr/eng/brd/m_65/view.do?seq=11. Accessed September 12, 2020. 2020.

22. Kim M-N: What Type of Face Mask Is Appropriate for Everyone-Mask-Wearing Policy amidst COVID-19 Pandemic? J Korean Med Sci 2020, 35(20). 
23. Lee SA, Hwang DC, Li HY, Tsai CF, Chen CW, Chen JK: Particle Size-Selective Assessment of Protection of European Standard FFP Respirators and Surgical Masks against Particles-Tested with Human Subjects. $J$ Healthc Eng 2016, 2016.

24. Kyung SY, Jeong SH: Particulate-Matter Related Respiratory Diseases. Tuberc Respir Dis (Seoul) 2020, 83(2):116-121.

25. Zimmermann M, Nkenke E: Approaches to the management of patients in oral and maxillofacial surgery during COVID-19 pandemic. J Craniomaxillofac Surg 2020, 48(5):521-526. 